\title{
Towards a Human City
}

\section{By Côme Bastin}

Josyane Franc is Head of International Affairs at the Cité du design and the Saint-Étienne School of Art and Design (ESADSE). She coordinates Saint-Étienne UNESCO City of Design and has been leading Human Cities_Challenging the City Scale since 2014.

\section{B. For the past four years the Human Cities project has been all about "challenging the city scale". What does that mean exactly?}

J. F. It means many things, it's a very broad idea. We can think about the city scale in different ways; it's not only about size. When we discussed the topic with our partners, many had their own interpretations. We discussed scales of organisation, scales of governance, scales created by digital technology. In spatial terms, it's about the places where people live, such as their streets and their neighbourhoods. And for example in organisational terms, it's about how these streets and neighbourhoods connect to each other. In any case, the important thing is that people feel disconnected from the various scales of the city and this is what we want to change. We want to reinvent the city with people.

\section{B. Why do you believe cities need to be reinvented?}

J. F. In many respects, things have got worse in cities in recent times. This is something we see very clearly in Saint-Étienne, but it's true for other cities as well. For example, city centres are no longer the lively places they used to be. Many shops are empty because people go to supermarkets in the suburbs or shop online. In fact, we tried to address this issue in one of our experiments in Saint-Étienne called "Ici Bientôt", which you can read about in this book. At the same time, young families in particular are leaving the city centre and moving to the suburbs. This affects urban demographics and also causes problems like congestion. So the city has become unbalanced and this is what we need to address.

C. B. And you think normal citizens should help with that.

J. F. Yes, of course, because they are the ones who need to be happy in our cities! If people are not happy, they will move to other cities or the suburbs. Many politicians still don't understand this and don't respond to what people need. And this is where democracy on a local level has to change. Just having elections isn't enough; what we need to do is really involve people in reinventing their city for decades to come. This is not to say that we don't need politicians anymore, but modern governance can't be done by top-down decision-making as has been the case for so long. And in the same way, we can't reinvent cities through megalomaniac masterplans that try to create a perfect city.

C. B. Do we still need designers in that case or have they become superfluous? 
J. F. Designers are still important. Richard Florida and Charles Landry explain how cities can be transformed with the help of their creative residents, like designers, artists, and so on. But I think the role of designers has changed. It's no longer about getting a bit of input from residents when you develop plans for the city, but about entering into a genuine collaboration. Designers should use their skills to translate people's needs into services and products that make the city better. And they should ideate, prototype and test solutions together with them. We see this happening in more and more places: it's a movement, and so not driven by economics. The designers I've met who are engaged in this aren't doing it for the money; there isn't much money in it. They're doing it because they want to change society. It often happens on a small scale, but if we all do something on a small scale we'll achieve big things together.

\section{B. When did you become interested in this new movement?}

J. F. For us at Cité du Design it started in 2008 when we organised the City Eco Lab exhibition at the Design Biennale. John Thackara was the curator; he's one of the contributing authors of this book and a leading expert on civic innovation. It was a turning point for us, as we really started to understand what this whole idea of bottom-up change was about. From then on, we felt we had to work with local communities and try to make a change at the local level. For example, during the City Eco Lab we ran a project called "Cantine Moins de $80 \mathrm{Km}$ ", a canteen which sourced all its food from within a radius of $80 \mathrm{~km}$ around SaintÉtienne. $80 \mathrm{~km}$ is a critical distance, because once you go over that you have things like additional regulation and refrigeration to worry about. After the Biennale, the idea was implemented in a school canteen and then the Mayor of Saint-Étienne included organic, locally sourced food in the city's school food policies. That's when we realised we could change things by experimenting. We prototyped and tested a solution and it became mainstream. At the time, this was still a relatively unusual process. But now there is a lot of experimentation going on, not only in France but also internationally.

\section{B. As Human Cities demonstrates... What made you want to lead the project?}

J. F. Cité du Design was one of the partners of the second edition of Human Cities, which ran from 2010 to 2012 and was about reclaiming public space. I'm very grateful to Lise Coirier of Pro Materia for involving us. Lise launched Human Cities in 2008 and invited several partners at different points. We really enjoyed being part of the project and were keen to be involved in the third edition. And since we had had the experiences I just talked about, and many others, we felt we had the know-how and the methodologies to play a leading role. We also thought it would be helpful for the work we were doing on social design. Saint-Étienne has a long design tradition, but it's a city of engineers. There's a strong focus on industrial design and the connection of design to economic development. What we wanted to do was complement this tradition by showing that design can also be a tool for social innovation. That is of course what Human Cities is about: using design to improve the city together with people.
C. B. One of the first things you did as project leader was radically expand the Human Cities network. What was your reason for that?

J. F. We wanted to have a wide range of partners with different backgrounds, different skills, and different areas of expertise. And we're very happy with the partners who have joined us! We have major universities like Politecnico di Milano and Aalto University, design institutes like Zamek Cieszyn and the Estonian Association of Designers, and smaller organisations like UIRS Ljubljana, Clear Village and Belgrade Design Week. We also wanted to have partners from other UNESCO Cities of Design, and we're very pleased that Bilbao Ekintza and FH Joanneum from Graz came on board. One of the things we wanted to do was examine how much bottom-up activity there already was across Europe, so obviously it was important to have partners from a range of countries. We also hoped that a large partner group would lead to many interesting experiments.

\section{B. And did it?}

J. F. Yes, definitely. What has really struck me about the experiments is their diversity. Each city interpreted the brief completely differently, and as a result, we've had a wide variety of projects addressing many different issues and involving many different people: artists in Bilbao, high school students in Helsinki, makers in London. To be honest, we in Saint-Étienne sometimes found it hard to see where a partner was going with their experiment, but in the end everything fell into place. And it wasn't only the experiments that showed this diversity; it was the same with other parts of the project like the Human Cities exhibition that travelled to each partner city. In Milan, for example, the exhibition was presented as something of a travelling circus with giant balloons. But in Ljubljana, it was based on the thirteen shared values we had defined at the start of the project. Another highlight for me was the exhibition in Graz; it was designed as a minigolf course and was very playful and fun.

\section{B. Having fun has been an important part of the project.}

J. F. Yes, it has. When you have so many partners it can be a real challenge to make sure everyone works together, but fortunately we never had any problems. Everyone was always very constructive and wanted to collaborate rather than compete. It's interesting; the European Commission is generally very keen on things like capacity building and skills exchange when it funds projects. We never really spoke about these things, but I think we achieved them and they're important legacies of the project.

\section{B. Speaking of which: what will happen to Human Cities in future?}

J. F. The future is looking bright! We're already preparing the next edition of the project, which will be led by Politecnico di Milano. After focusing on experiments during this edition, we're now going to look at what happens afterwards. What impact and legacy do experiments have when they're finished and how can we improve their impact and legacy? Most of the current partners want to be involved 


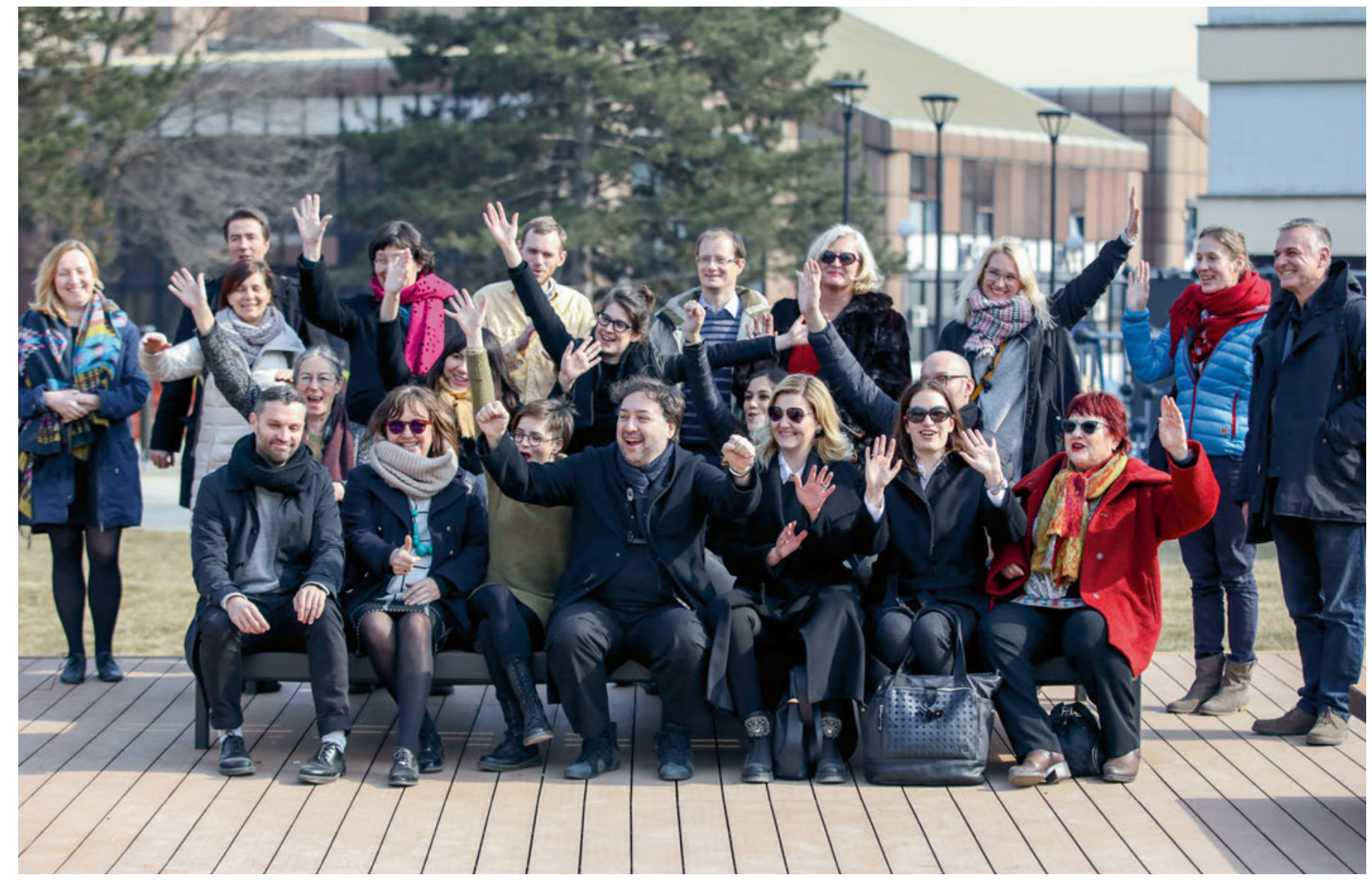

Human Cities partners celebrating the opening of Kragujevac Creative Grand Park (Serbia) in February 2017. ( B Belgrade Design Week

in the new edition, which is a good indication of the success of the project. Apart from that, it also looks as if we're going to expand internationally. We've been invited by Seoul Design Foundation to a conference in September 2018 where we will present Human Cities and where Human Cities Asia will be launched. They're going to start the same way we did in 2014 , by collecting case studies and best practice from around the continent.

C. B. So your future might be in Asia?

J. F. Perhaps! I have an appointment now with a Chinese curator, so that could be a sign. 


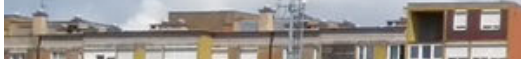

u

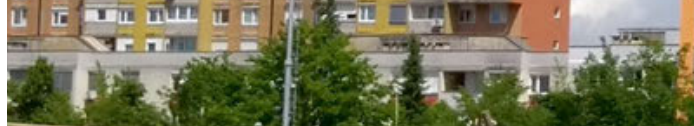
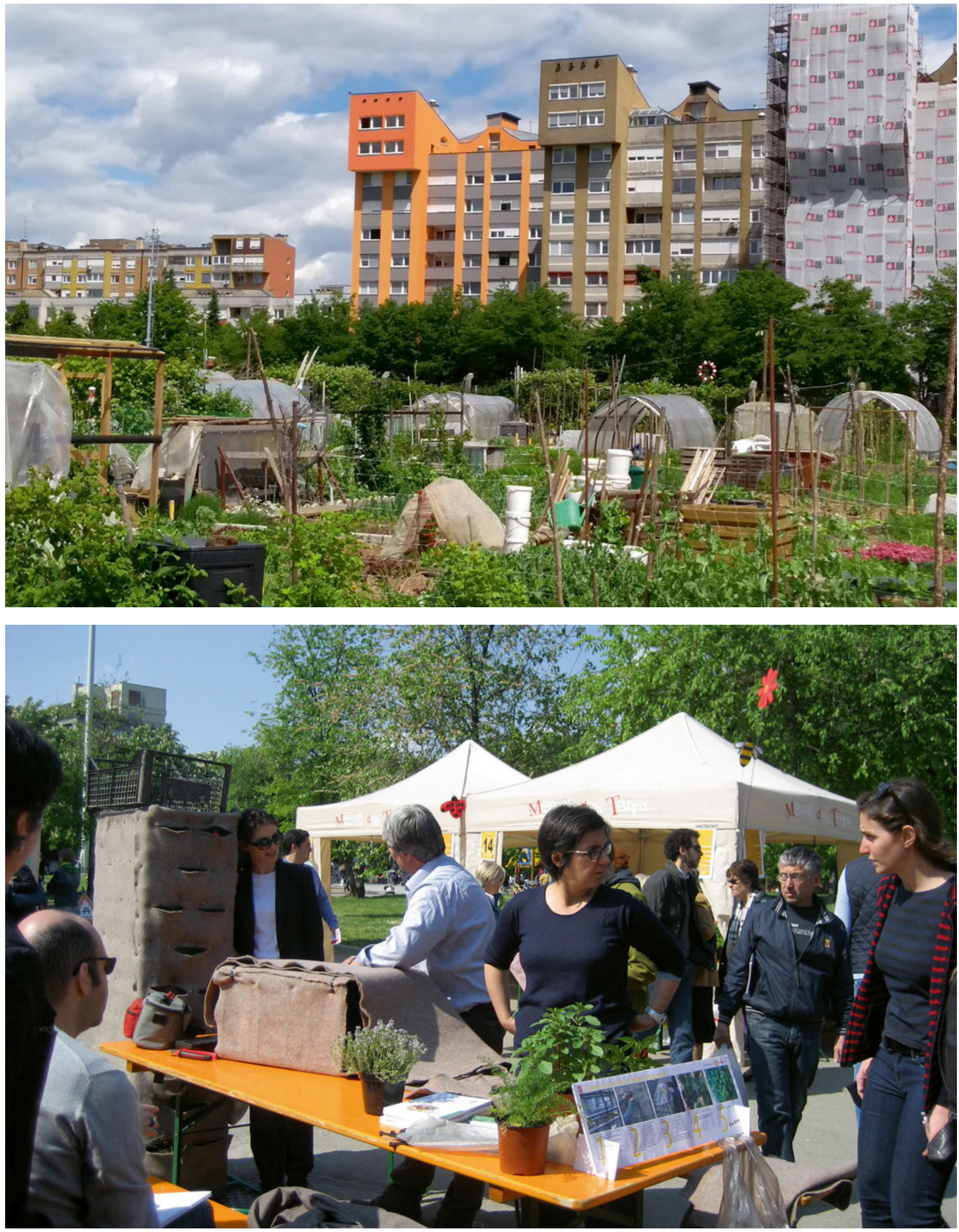